\title{
Evaluation of the Variables Affecting on the Cost Management and Its Correlation to the Implementation of Construction Projects
}

\author{
Aswan S. Al-Dalaeen \\ Al-Balqa Applied University, Karak University College
}

\begin{abstract}
Profit is the main goal for any project and there is no profit if there is no control and adjust the cost. Therefore, This study aims to measures the extent of project managers recognition of the concept of cost management and to highlight the variables affecting the cost management in construction projects. To achieve the objective of this study, the researcher has developed a questionnaire including six main axes (design, financial aspect, work site, project management, communication between the three project parties, implementation of the project), including 30 variables that affect directly on the cost management in construction companies and consultants' offices. This study has concluded two main results. Firstly, project managers have the responsibility for controlling and adjusting the cost of projects. Secondly, The most important and affective variables are doing the designs required modifications quickly, Inflation, The existence of warehouses for the storage of materials at the site, develop a list of substitutes of materials and equipment if prices rise, Preparing quick and easy means for communication between contractor, owner and consultant and Contractor has previous experience of implementation similar projects.
\end{abstract}

DOI: $10.7176 / \mathrm{EJBM} / 11-2-02$

\section{Introduction}

Construction projects are considered a main factor on which the national economy depends on since there is no country could be developed without it. Due to Jordan is an economically developing country, it has witnessed a kind of revolution in the field of construction during the last ten years. As a result Jordan has become an attractive environment regarding to the circumstances of the surrounding countries in our region.

Generally, any construction project couldn't be finished successfully unless it has a successful management that works hard to achieve the objectives in time set and estimated cost by professional use of available resources and considering the special conditions of every certain project. Therefore, the engineering management in terms of effective planning and management of resources of equipment has a very vital role to be done through managing workers, subcontractors and to arrange the necessary procedures to ensure that the requirements are available in the right place and in the right time.

In this study, the researcher aims to deals with the cost management of construction projects in terms of being an important element of modern management, the most indispensable management processes especially in the field of planning all parties to the construction projects owners, contractors and supervisors. The increase of the cost of projects over the estimated value is one of the biggest challenges facing the projects managements especially in the current economic conditions and economic crises that leads to delay the time of delivery or implementation of projects at low quality levels.

Any project must go through many stages, as well as the construction projects that begin with the initial studies, the designing stage, the stage of tender, the stage of contracting, the implementation phase until it reaches the final stage of delivery. Therefore, the calculation of the cost at each stage of project life is calculated approximately. Then costs of the project is followed-up continuously to insure that the total budget does not exceed the owner estimated due to the stage of offering the tender contractors depends on the tender work to estimate the exact detailed cost in order to prepare prices for contracting. In case the tender is submitted to the contractor, the contractor conducts a detailed and accurate study of the drawings and a deep knowledge of the prices of equipment and materials to calculate the actual cost of implementation of the project. In the implementation phase, comparing process between the estimated cost and actual cost is conducted.

Project Cost Management is concerned with estimating the necessary financial resources for the project, combining the estimated costs and working on to control the budget of the project by monitoring the work in the project so that the work is accomplished within the specified budget framework, as well as controlling the deferent variables that affect the cost in different stages of the project life.

Cost management depends on many factors. Controlling these factors increases the effectiveness and efficiency of time and resources management. Estimating project costs requires accurate and professional planning that contributes in producing an appropriate cost management plan for the project where the cost of each item or activity is accurately calculated considering account changes within the permissible limits. Generally, project cost management is related to the most important requirements for successful completion of 
the project as identification of a financial framework to complete each stage of the project within time set considering that cost management is forecasts contributing in estimating expected costs of the project from the beginning phase to the delivery stage within a specified period of time.

\section{Study Problem:}

According to the researcher work experience she noted that; Firstly, the cost management of construction projects is one of the most important challenges facing this kind of project and it plays an important role in the success of these projects. Secondly, there is an important link between cost management and time management. Thirdly, there is a lack of awareness of most of the contracting companies for the importance of cost management and advance planning.

\section{Study Objectives:}

The study aims to:

1- Define the cost management and its relation to the implementation of projects

2. Highlight the concept of effective engineering management in terms of time management, cost management and resource management.

3 - Measure the awareness and interest of construction companies to manage the cost.

4 - Provide important information for the three parties of the projects, the owner, supervisor and contractor about the direct correlation between cost management and improving the quality and projects running out works .

\section{Study Importance:}

The importance of this study is derived from the fact that it is directly concerned with the construction projects which are considered as one of the most important economic and social projects in these days.

The study is also interested directly in the issue of cost which is one of the most important challenges facing projects engineering management. The ultimate goal of any profit project is to gain profit or to avoid the financial loss in the worst circumstances resulting from the lack of cost control. The study is concerned directly in project cost management to achieve profits and reduce problems at all stages of the project that would impose excessive costs.

In addition, the study focuses on the effective role of engineering management in balancing of the three determinants of the project, time, cost and quality. The general objectives of the project are to implement them in the shortest possible time, the lowest cost and the highest quality, while these objectives may conflict somewhat in which they may need a higher cost to achieve less time or vice versa .

\section{Previous Studies:}

The management of a cost of any project must include a set of processes and important procedures which are related to the project completion within the planned budget as the form shows these basic operations in construction projects(Pmbok,2003).

\section{Project Cost Management}

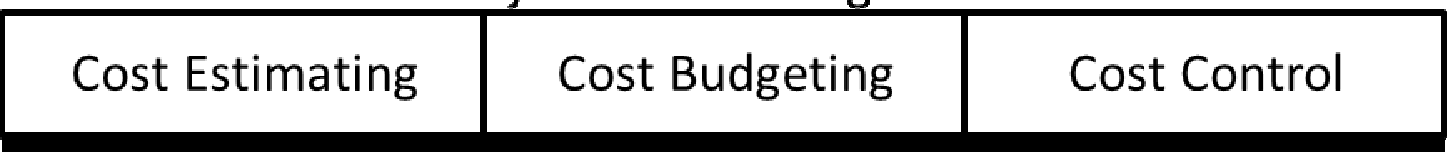

Figure 1:Basic Cost Operation

Cost Estimating is a process of forecasting of the materials quantities, equipment and labor that will be used to implement the construction project within the specified requirements and criteria which are a basic process for each project. The cost budgeting is a process which includes the implementation of the financial provisions of the contract. The cost control is the process of controlling any changes in the project budget. It is considered the most important process because it is associated with the project from the beginning of implementation until the final stage(Pmbok,2003).

Hendricson Study (2003) shows the role of the project plan to develop, measures and monitors the work progress and to identify the causes of changes to carry out the work for delivering it on planned time without increasing in the planned cost.

Taei and Sacco Study ( 2009) -A study of five pre-construction projects in Iraq - shows the lack of use of advanced scientific means in the field of cost management and planning could lead to poor efficiency in cost management and planning at all stages of projects completion. This study confirmed that the proper management and cost planning from the beginning of the project facilitate the process of controlling the project's cost.

Akkab Study ( 2009) has studied the factors that have an impact on increasing the cost risk. The researcher has concluded that the required designs are the most important factors which may affect on $80 \%$ of the project cost increase.

Aldeery study (2011)which is entitled as the impact of poor planning on the delay in the implementation of construction projects. The study has concluded that the most factors which causes the delay of construction projects occurred in the planning stage, which reflects the importance of planning in construction projects. The 
study has identified the ten most important factors contributing to the delay of the construction projects in Libya, which are the bad planning of the project, the scheduling of the financial difficulties facing the contractor, the poor estimates of cost, management and bad supervision of the work site, the inefficiency of the project team, the insufficient number of equipment, Structural difficulties in monthly payments, change in work demand, slow response of consultant, and inefficient subcontractors.

Zidan Study(2013) which was conducted on designers and contractors in Syria. This study shows that failure of giving designers enough time to design and choosing designers at the lowest prices affect on the performance of projects and increase the total cost.

Mohammed and Abdulrazzq Study (2014) This Study reveals that the cost control is done by recording all the financial expenses and the actual fund amounts that each project activity needs and comparing them with estimated costs.

Aldalaeen Study (2018) which is entitled as The Effective Factors on Quality in the Jordanian Construction Projects, that conclude the most important factors that affect on the quality of construction projects are cost of equipments and materials.

Study Methodology:

The Study has used the descriptive methodology to conclude the results. The researcher has developed a questionnaire to collect data from the project managers point of view who work in the field of construction projects. In addition, the researcher has collected many of the data from different sources such as books and magazines interesting in the research topic. The study also has conducted direct interviews with the people who are directly concerned and interested in the subject of research.

\section{Study Community and Sample:}

The study community includes the engineering sector of construction companies who are registered in the Contractors' Association and the offices of consultants in Jordan. This study is specifically directed to the managers of construction projects in Jordan to examine their point of views to study the impact of cost management on the completion of projects by using 60 questionnaires.

Data analysis and discussion of Results:

After collecting data by the questionnaire, a statistical analysis has been carried out to extract the final results. The results were as follows:

Firstly, Years of experience of study sample:

(Figure 2) shows the years of experience of the study society. The study has found out that the percentage of study sample whose experience is more than 30 years reached $42 \%$. This indicates the accuracy and importance of the information that were filled by them have been derived from their long experiences.

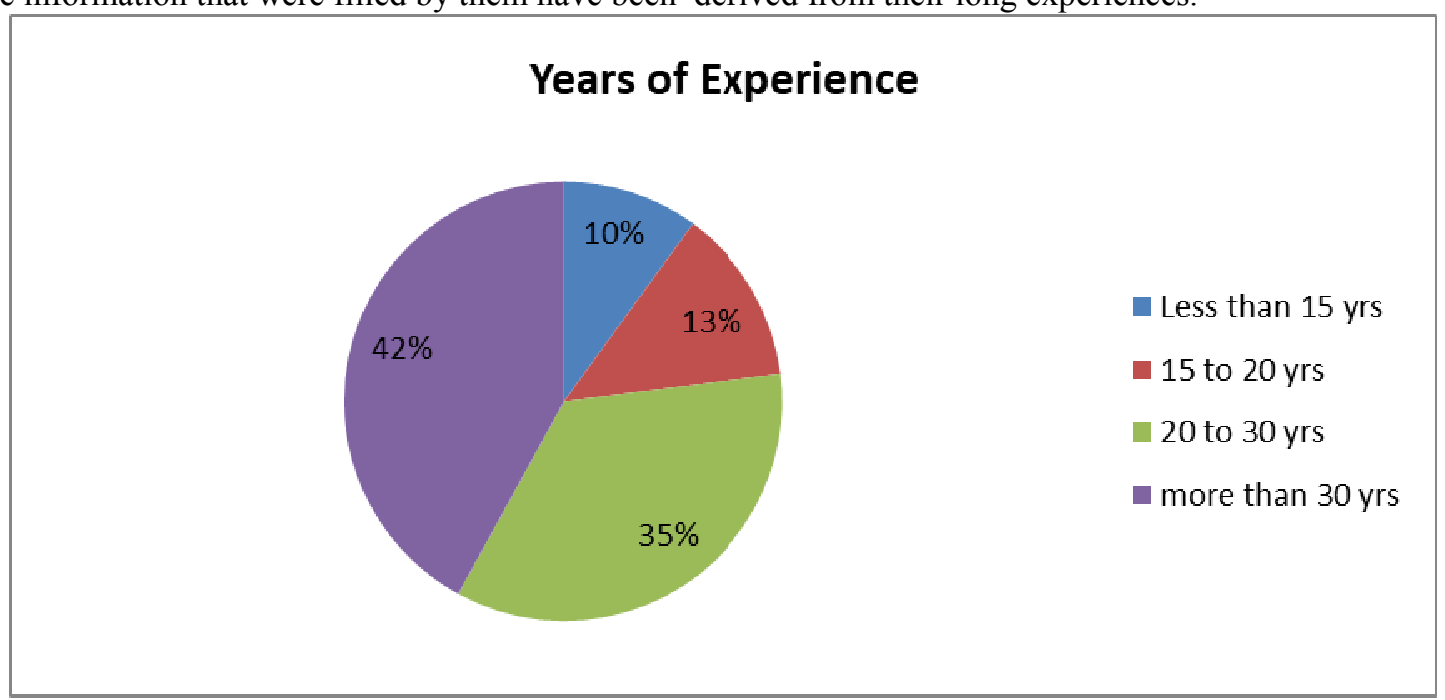

Figure 2:Percentages According to Years of Experience

Secondly, education level of the study sample:

(Figure 3) shows the level of education of project managers. The percentage of project managers who have a master's degree is $45 \%$, and this ratio indicates the quality of the study results. The percentage of project managers who have a bachelor's degree is $33 \%$. The percentage of project managers who have a $\mathrm{PhD}$ and is $22 \%$. 


\section{Educational Level}

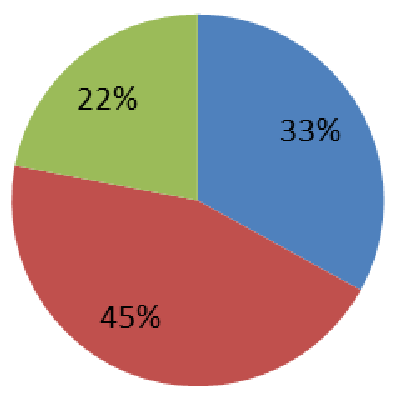

Bachelor Degree

Master Degree

$\mathrm{PhD}$

Figure 3: Percentages According to Educational level

Thirdly, Project Type:

(Figure 4) shows that due to the urgent need for construction projects in various types such as homes, schools, hospitals ... etc, most of the projects that carried out by project managers are construction projects where it's percentage is $56 \%$.

\section{Types of Projects}

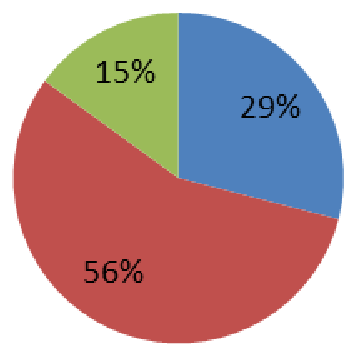

- Highways Projects

Construction Projects

- Other Projects

Figure 4: Percentages According to Types of Projects

In this research a questionnaire including six main axes (design, financial aspect, work site, project management, communication between the three project parties, implementation of the project), including 30 variables that affect directly on the cost management in construction companies and consultants' offices.

Calculate the arithmetic mean for the answers as follows:

Table( 1)

\section{Mean for Design}

\begin{tabular}{cc}
\hline Dimension & Mean \\
\hline Design requirements are not understandable. & 2.81 \\
\hline Continuing changes in design. & 2.85 \\
\hline Designs are not accurate. & 2.84 \\
\hline Doing the designs required modifications quickly. & 2.88 \\
\hline
\end{tabular}

Table( 1) shows that according to project managers perception the speed in making the required modifications variable has the highest affect followed by continuing changes in design variable while the inaccurate designs variable has the lowest affect. 
Table(2)

Mean for Financial Aspect

\begin{tabular}{cc}
\hline Dimension & Mean \\
\hline Fluctuation in the prices of materials and equipments. & 3.29 \\
\hline Cost of transportation of equipment and materials. & 3.32 \\
\hline Cash flow availability of the contractor. & 3.26 \\
\hline The cost of renting equipment & 3.28 \\
\hline Workers' remuneration rates & 3.25 \\
\hline Inflation & 3.30 \\
\hline
\end{tabular}

(Table2) shows the most influential variables on cost management within the second axis, which emerged based on calculation of the arithmetic mean that inflation has a significant and significant impact on the cost of construction projects, which may lead to exceeding the estimated cost.

Table(3)

Mean for Work Site

\begin{tabular}{rrc}
\hline & Mean \\
\hline & Project implementation site. & 2.54 \\
\hline Removing obstacles from the workplace. & 2.23 \\
\hline The presence of warehouses for the storage of materials at the site. & 2.39 \\
\hline
\end{tabular}

The table above shows that the variables of the third axis have the least impact on the cost of the project among the six axes, while the site of implementation of the project has the most influential affect among the other variables.

Table( 4)

Mean for Project Management

\begin{tabular}{lc}
\hline \multicolumn{1}{c}{ Dimension } & Mean \\
\hline The commitment to the project timeline. & 3.62 \\
\hline Inaccurate planning by the Contractor & 3.65 \\
\hline Initial cost estimating & 3.75 \\
\hline Recruitment of qualified and experienced staff. & 3.7 \\
\hline Setting accurate and detailed amounts tables. & 3.77 \\
\hline Develop an appropriate organizational structure for the project. & 3.72 \\
\hline Develop a list of substitutes of materials and equipment if prices rise & 3.79 \\
\hline
\end{tabular}

According to the table above, It is noticeable that project management has a significant impact that cannot be ignored as it emerged from the answers that the project management plays the most important role in controlling the cost and avoiding it from exceeding the planned budget, while from the point of view of project managers, the management should develop a list of substitutes of materials and equipment in If prices rise or if the equipments are not available to avoid delay the implementation of the project.

Table( 5)

Mean for communication between the three parties of the project Dimension

Hold periodic meetings between the contractor and the owner and the consultant. Mean Preparing quick and easy means for communication between Contractor, Owner and Consultant.
Making periodic financial reports from the contractor to the owner and consultant

As it has been shown in the table above, the variable of preparing quick and easy means for communication between contractor, owner and consultant has a significant affect . it is necessary to prepare periodic financial reports from the contractor to the owner and consultant, too.

Table(6)

Mean for Implementation of the Project

\begin{tabular}{lc}
\hline \multicolumn{1}{c}{ Dimension } & Mean \\
\hline Contractor's lack of equipment and incapability to hire. & 3.5 \\
\hline The existence of a department to control and manage the cost. & 3.55 \\
\hline The existence of the department of quality control. & 2.9 \\
\hline The existence of the department of planning & 3.25 \\
\hline Contractor has previous experience of implementation similar projects. & 2.87 \\
\hline Contractor experience in construction projects. & 3.21 \\
\hline Use of modern methods of implementation & 2.79 \\
\hline
\end{tabular}

(Table6) shows that, according to project managers perception, any project should have a specialized 
department for cost control and management that monitors cost and prepares reports continuously. Project managers say that the ownership of equipments is better than renting them because it leads to more cost control.

\section{Conclusion}

The objectives of this research have been achieved, which is a study of the variables affecting cost management and its correlation to project implementation. The following conclusions were also reached:

1 - It is very known that the project cost is one of the most important challenge facing of any project. It is difficult to find quick solutions. The solution should be figured out by all workers in the project. It is the responsibility of management to control the cost not to exceed the planned budget .

2- Detailed and accurate study of any project, knowledge of the requirements of the owner accurately, market study and the development of alternatives of materials with appropriate cost if prices rise are the main tasks for project managers live control of the cost.

3- In general there is a weakness in the application of the foundations and instructions of engineering management in the engineering projects, especially construction. In addition to non - compliance with the timetable for the project, we must recognize that there is a strong correlation between the cost management and implementation of projects in terms of time and quality and cost. Where the importance of cost increases and the importance of time is reduces while the importance of quality becomes at the medium ratio at the beginning of the life of the project. However, the cost is important throughout the life of the project, while the importance of quality increases with the importance of time in the rest of the project.

\section{References}

Akkab,S.N.(2009). Study of Design and Implementation Factors that Leads to the Increase of Project Cost Risks During Construction Stage. Journal of Engineering and technology, Vol.27, No. 12.

Aldalaeen,A.(2018). The Effective Factors on Quality in the Jordanian Construction Projects. iiste .Civil and Environmental Research, Vol.10, No. 10.

Aldeery,A. (2011). The Impact of Poor Planning on the Delay in the Implementation of Construction Projects. Arab British Academy for Higher Education

Handrickson, C."Project Management for Construction Planning" 2nd edition. Prepared for WWW Publication, Ce.Cmn.edu, Version $2.1,2003$

Mohammed,S.R and Abdulrazzq,H.(2014) Development a Proposed System of Organization Structure to Management Multi Construction Projects. Journal of Engineering, Vol.20, No. 8.

Pmbok guide, " A Guide to the Project Management Body of Knowledge" 2000 Edition, Project management institute newtown square, pennsylvia USA, Library of Congress Cataloging in publication Data, 2003.

Taei,M. and Sacco,Z (2009). Cost Management and Planning Construction Projects. Journal of Engineering, Vol.15, No. 4.

Zidan,A. (2013) Factors that affecting on design quality of Construction Projects in Syria. Journal of Damascus university, Vol.29, No. 2. 